\title{
Human-robot collaboration in assembly processes
}

\author{
Ivan Antoniuk ${ }^{1}$, Martin Krajčovič ${ }^{1}$,Olha Kolesnyk ${ }^{1}$ \\ ${ }_{1}$ University of Žilina, Faculty of Mechanical Engineering, Department of Industrial \\ Engineering \\ Univerzitná 8215/1, 01026 Žilina, Slovakia \\ ivan.antoniuk@fstroj.uniza.sk \\ martin.krajcovic@fstroj.uniza.sk \\ olha.kolesnyk@fstroj.uniza.sk
}

\begin{abstract}
Annotation: In the conditions of strong market competition and everincreasing customer requirements, there is a need to produce more types of products in smaller batches. Robotic systems often cannot meet the demands of such flexibility, and therefore some operations can only be performed by humans. One solution to achieve the required flexibility is to combine an appropriate level of automation with human skills. The general importance and reason for cooperation with robots is related to the need and possibility of combining repeated and controlled performance of robots with the skills and reactive abilities of operators. In general, humans have an excellent ability to perform tasks in an unstructured and inaccurate environment, while robots perform tasks with precision, power, and control.
\end{abstract}

\section{Introduction}

Robots are used in repetitive and deterministic operations within production lines or at robotic stations and perform various operations - from object handling, machine operation, assembly to welding and painting processes. Typically, these systems are fully automated isolated cells and operate separately from the operators to ensure complete security. Although robots are characterized by their flexibility, they are generally not as flexible as expected. The application of automation requires adequate and consistent processes with large production volumes. In the case of product variability, the processes should be similar so that task programs and algorithms can be adapted in the case of product variability. [1]

The requirements of the current market are associated with high demands on the variability and diversity of products. As a result, the product range is expanding, and the batch sizes are lower. Traditional automated systems can no longer handle such diversity due to a lack of flexibility, and this is one of the reasons why some products are usually assembled by highly qualified workers.

As a solution to achieve the required flexibility of the assembly system is a combination of an automated system and human work. Thanks to the unique cognitive and sensorimotor capabilities of man, the operator is able to perform assembly steps that today's assembly systems cannot automate. The 
experience and creative thinking of the operator allows to find a solution even for unstructured or incomplete defined tasks. In contrast, the robot can facilitate the work of the operator by, for example, carrying heavy weights or taking on monotonous activities. The effective division of activity between a human and a robot increases the productivity of the entire workplace and at the same time relieves the person of muscular and mental strain, reduces the level of stress and increases safety in the workplace. Collaborative assembly cells have high flexibility and can quickly switch between different products and produce even in smaller batches. [1]

\section{Influencing factors of human-robot collaboration}

The interaction between a human and a robot is influenced by several factors. According to Rahimi and Karwowski [3], human-robot interaction systems can be divided into various influencing factors. The authors define this type of interaction system as an n-tuple:

$$
\mathrm{HRIS}=(\mathrm{T}, \mathrm{U}, \mathrm{R}, \mathrm{E}, \mathrm{I})
$$

where:

HRIS - human - robot interaction system,

$\mathbf{T}$ - represents the task requirements,

U a $\mathbf{R}$ - characteristics of User and Robot,

E - environment of interaction,

I - set of interactions.

The requirement for user tasks and characteristics can be divided into cognitive and physical characteristics, while the characteristics of the robot consist of software and hardware aspects. It follows that the interaction between a human and a robot can be influenced by many different factors (Fig. 1), although it depends on the type of interaction. [2] 


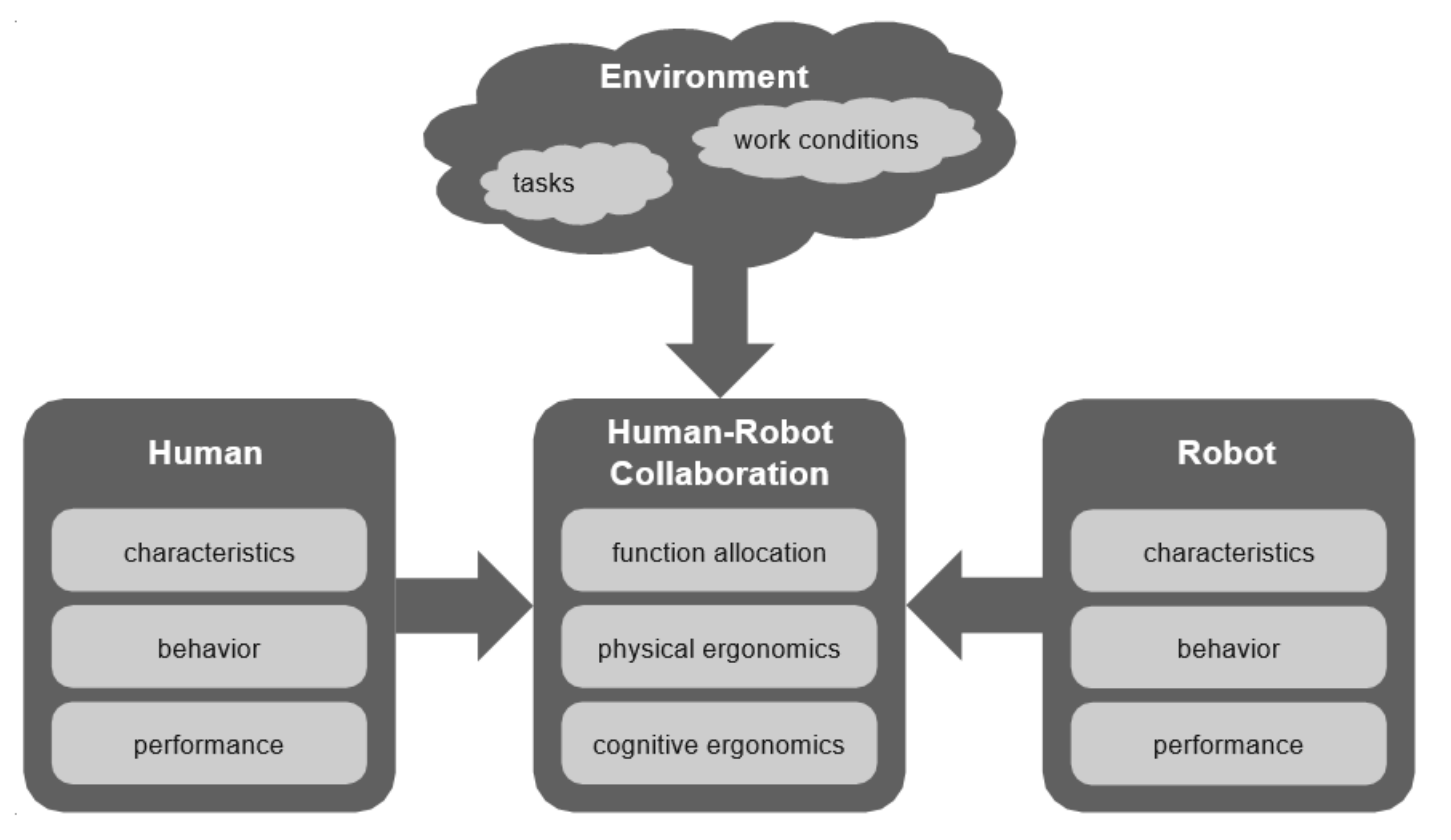

Figure 1 - Influencing factors of human - robot collaboration [2].

Depending on the influencing factors of human, robot and environment, different optimization criteria can be derived for the design and evaluation of this type of cooperation (Table 1). Therefore, the planning of the joint workplace as well as the division of tasks should be focused mainly on the mentioned optimization criteria. The optimization criteria include the division of functions, it means if the given assembly step is performed by a human or a robot. [2]

Table 1 - Optimization criteria for human-robot collaboration

\begin{tabular}{|c|c|c|}
\hline Category & Human & Robot \\
\hline \multirow{4}{*}{ Tasks division } & Availability & Availability \\
\hline & Feasibility & Feasibility \\
\hline & Realization time & Mountability \\
\hline & & Realization time \\
\hline \multirow{2}{*}{ Physical ergonomics } & Ergonomic risk & \multirow{2}{*}{-} \\
\hline & Substitution human-robot & \\
\hline \multirow{2}{*}{ Cognitive ergonomics } & \multirow{2}{*}{-} & $\begin{array}{c}\text { Transparency of assembly } \\
\text { sequence. }\end{array}$ \\
\hline & & Transparency of robot behavior. \\
\hline $\begin{array}{l}\text { Environmental } \\
\text { ergonomics }\end{array}$ & $\begin{array}{l}\text { Work conditions (e.g. } \\
\text { noise, lightning, } \\
\text { temperature) }\end{array}$ & - \\
\hline Technical & - & Tool change \\
\hline
\end{tabular}


Operator availability is limited by various factors such as job rotation. The availability of the robot can be affected by e.g. the principle of shared resources, alternating service of workplaces or simply a technical outage. The basic feasibility of assembly steps by either a human or a robot is also a fundamental criterion. In relation to humans, feasibility is primarily based on experience and skills, the limitation may be e.g. heavy component weight or insufficient training. The feasibility of the robot is limited mainly by its technical specification, such as the type of gripper, etc. The last influencing factor for the division of tasks is the time of the assembly step. From an economic point of view, it seems advantageous to assign the assembly to a source that runs faster, which can optimize the overall product assembly time, but sometimes economic criteria may conflict with others, e.g. ergonomic. If the operator's workflow changes too often, there could be an increase in mental strain or a situation that could endanger human health. [2]

\section{Ergonomic conditions}

The design of the workplace and the operation should take into account ergonomic working conditions, including physical, cognitive and environmental ergonomics. Physical ergonomics includes the assessment of ergonomic risk as well as the number of changes in workflows between man and robot. It is necessary to completely avoid assembly steps, which are associated with poor ergonomic conditions, resp. their number should be reduced to a minimum. Similarly, in the case of robot performance, the number of changes in work activity should also be minimal, as frequent changes in robot activity increase the risk of danger to the operator or there may be a misunderstanding between a human and a robot. [3]

Other influencing factors of human-robot cooperation can be established in environmental conditions. For example, noise exposure or temperature stress significantly affect human performance. In addition, insufficient lighting in the workplace prevents stress-free work. Cognitive ergonomics consists of transparency of assembly steps and robot behavior, it is influenced by mental workload and predictability. The assembly procedure is chosen regarding three conditions [4]:

- Components that are mounted in close proximity to already stored components are preferred.

- $\quad$ The product is mounted parallel to the mounting surface.

- The product is assembled in assembly groups.

The more conditions considered during planning, the less the mental strain on the human operator interacting with the robot. The behavior of the robot itself can change in terms of speed and trajectory of its movements. Anthropomorphic velocity and trajectory profiles significantly increase the predictability of robotic actions, which is essential for interaction.[4] 


\section{Example of the collaborative workplace}

Collaboration means cooperation in a shared workspace. This requires special security measures that apply not only to hardware and software, but also to other issues such as risk assessment, workstation design and tasks to be performed, documentation, training, etc. The overall arrangement of the robotic station in cooperation with the operator is shown in the figure 2 . The robotic station has standard protection measures that ensure safe operation in full automation mode. In the collaboration mode, there is a specific common space where both the robot and the operator intervene, in this case the space is monitored by security scanners, which ensure that no person enters the work space that does not belong to the cooperation. During collaboration, there may be different ways of interacting - which involve direct contact or just working at close range. [1]

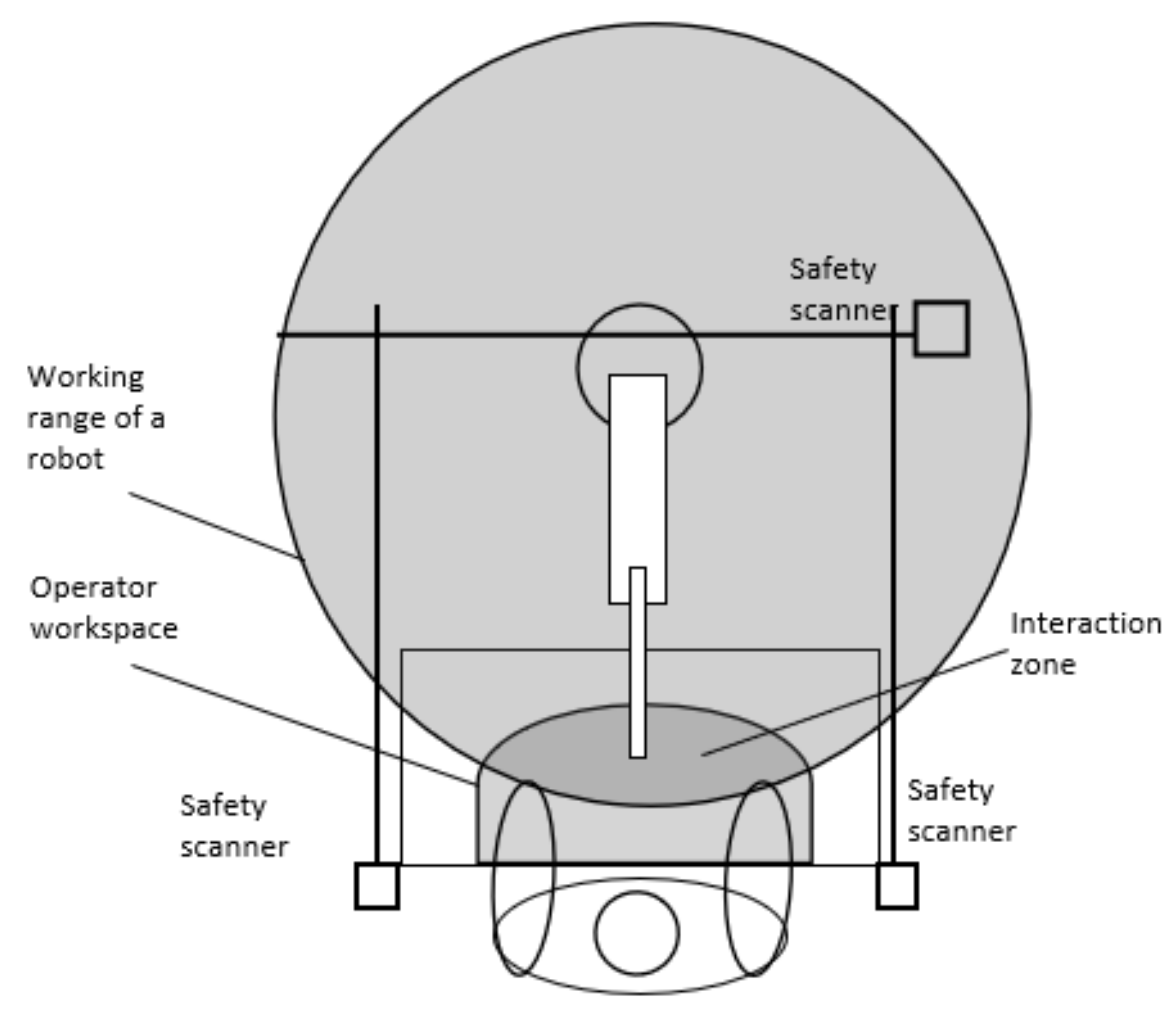

Figure 2 - Schematic illustration of a collaborative workplace.

For a collaborative workspace, the priority is to eliminate or reduce the hazards or risks that can be foreseen during the performance of shared tasks. These facts should be considered during this design process [1]:

- Set limits of space for cooperation,

- Defined approach and conditions of cooperation,

- Identification of ergonomic problems related to the human-machine interface, 
- Identification of restrictions of cooperation.

Using software such as Tecnomatix Jack from Siemens or CERAA from CEIT, it is possible to correctly design a workspace and a detailed layout of the workplace regarding to ergonomic regulations and applicable legislation.

\section{Conclusion}

There are several reasons for the implementation of combined collaborative workplaces, whether it is an effort to relieve a person from excessive physical and mental stress or the inability to fully automate certain processes. Unlike in the past, when robotic workplaces had to be fenced, nowadays this kind of cooperation is feasible. The main benefits of human-robot collaboration are relieving humans of hard work, increasing production efficiency and the ability to produce a wide range of products in small batches. The kind of robothuman collaboration is interesting in many cases and opens up a new opportunity in tasks and applications that cannot otherwise be automated with robots.

\section{Acknowledgments}

This work was supported by the Slovak Research and Development Agency under the Contract no. APVV-19-0305.

\section{References}

[1] BOLMSJO, G., BENNULF, M., XIAOXIAO, Z. Safety System for Industrial Robots to Support Collaboration. In: Advances in Ergonomics of Manufacturing: Managing the Enterprise of the Future. Florida, USA, 2016, 253 - 265. ISBN 978-3-319-19502-5.

[2] FABER, M., KUZ, S., MERTENS, A., SCHLICK, Ch. M. Model-Based Evaluation of Cooperative Assembly Processes in Human-Robot. In: Advances in Ergonomics of Manufacturing: Managing the Enterprise of the Future. Florida, USA, 2016, 101 - 111. ISBN 978-3-319-19502-5.

[3] RAHIMI, M., KARWOWSKI, W. A research paradigm in human-robot interaction. Int. J. Ind. Ergon, 1990, 5, 59-71.

[4] MAYER, M. P., ODENTHAL, B., FABER, M., WINKELHOLZ, C., SCHLICK, Ch. M. Cognitive engineeringb of automated assembly processes. Human Factors Ergon. Manuf. Service Ind., 2012, 24(3), 348-368.

[5] FUSKO, M., BUČKOVÁ, M. Smart technologies in future factories. Technológ, 2019, 11(2), 79-84. ISSN 1337-8996.

[6] BARBUŠOVÁ M., BIGOŠOVÁ E., ČECHOVÁ I. Systém merania productivity v podniku. In: Projekt interdyscyplinarny projektem XXI wieku. Wydawnictwo Akademii Techniczno-Humanistycznej: Bielsko-Biała, 2018. ISBN 978-8365182-92-0. 